\title{
Preparation of Porous Materials for Backscatter Electron Imaging: Some Observations on Metallurgical Grade Coke
}

\author{
James H. Steele Jr. Ph.D. C Consultant, 2019 Nova Road, Pine, CO 80470
}

The preparation of porous materials for examination by backscatter electron (BSE) imaging with an SEM may be carried out by impregnating open porosity with a low melting liquid metal under pressure followed by standard polishing procedures [1]. Open porosity with sizes greater than about $25 \mathrm{~nm}$ can be filled using a pressure of $10 \mathrm{ksi}$ in a standard mounting press adapted with o-ring holders to contain the liquid metal. Low melting Bi-Sn alloys, such as "cerrotru" (58\%Sn-42\% Bi), provide the best infiltrates as they tend to expand during solidification. A significant advantage of liquid metal impregnation is the ability to apply argon-ion etching to reveal microstructural detail. The main disadvantages are cost, and the difficulty in obtaining a good final polish for optical microscopy.

Petrographic analysis of coke microstructure is usually conducted using optical microscopy, where cellwall thickness, mean pore size, and volume fraction $\left(\mathrm{V}_{\mathbf{v}}\right)$ of porosity are estimated [2].

Two cross sections through a metallurgical grade coke samples with different stability values for blast furnace performance are presented as BSE images in Figure 1. This foamed microstructure consists of thin walls of solid carbon with large rounded open porosity. Computer controlled SEM measurements were obtained using digital beam controlled line scan analysis [3], wherein chord length distributions were measured. The lineal scan data provide stereological estimates of volume fraction ( Vvv), surface area $(\mathbf{S v})$, and mean chord length $(\square)$ through the solid and porosity of the coke. The stereological estimates for these three parameters for the two different stability coke samples are listed in Figure 2 along with histograms of the chord length distribution data. Application of this same technique for stereological analysis of carbon-carbon composites was reported previously [4]. The stereological lineal analysis results will be discussed in detail in the presentation.

References

[1] E.T. Rose, and L.F. DeRoos, Microstructural Science Vol. 1, Elsevier, N.Y. (1974) 275-281.

[2] D.E. Pearson, Advances in Western Canadian Coal Geoscience, Forum Proc. (1989) 174.

[3] G.S. Casuccio, et al., APCA Journal, 33 (no. 10) (1983) 937.

[4] J.H. Steele Jr., Microsc. Microanal. 8 (Suppl. 2) (2002) 1248CD. 

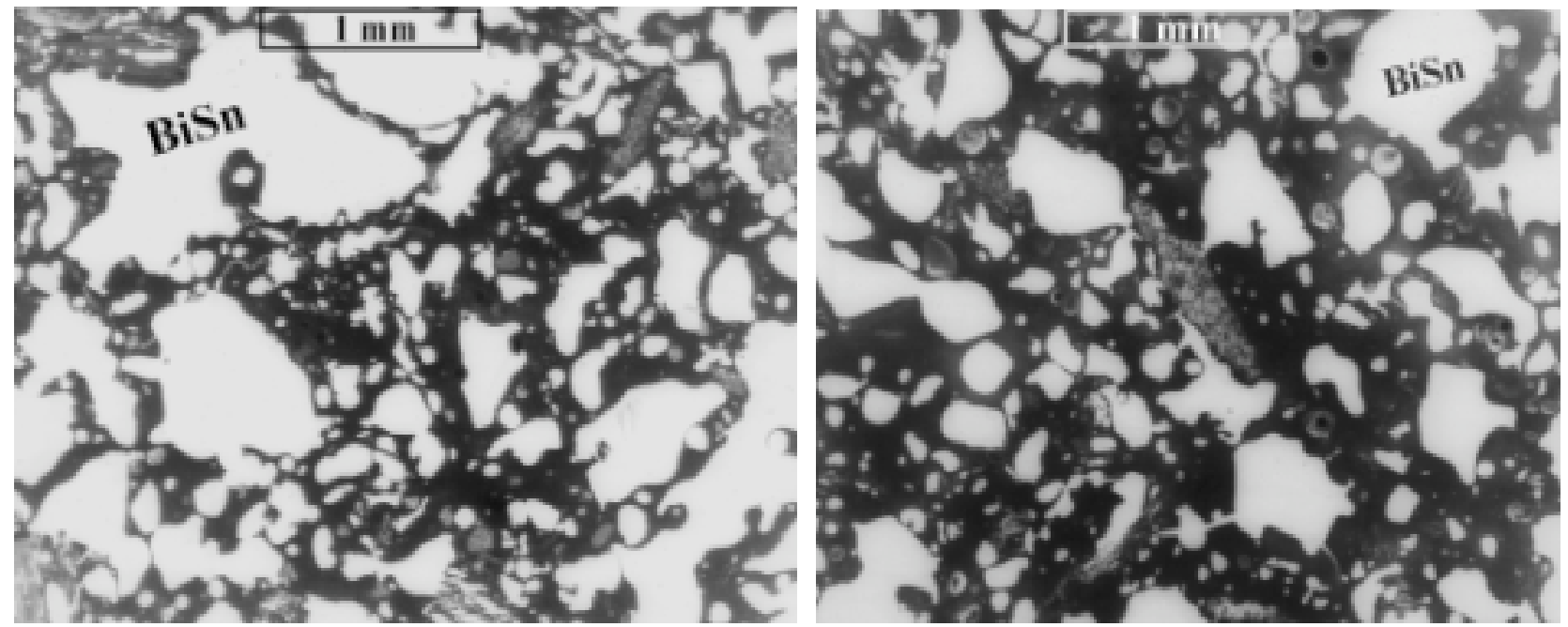

Figure 1 Backscatter images of Coke samples with a stability index of 51.5 (left) and 61.5 (right).

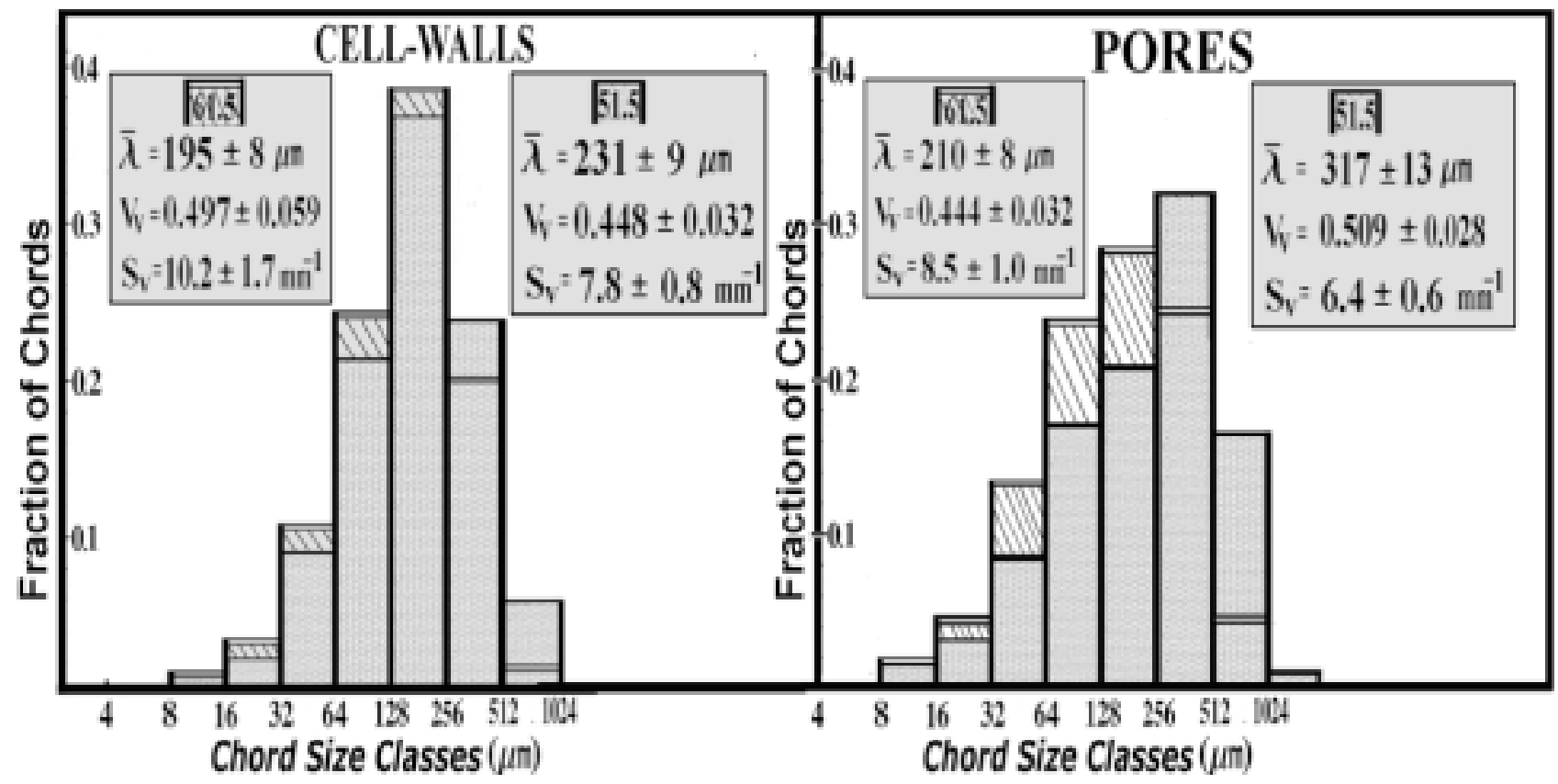

Figure 2 Histograms showing chord length distributions for the cell-walls and pores in the two coke samples with stabilities of 61.5 and 51.5. Mean chord length $(\square)$ and volume fraction $\left(\mathbf{V}_{\mathbf{V}}\right)$ measured by lineal analysis using digital beam scans with a computer controlled SEM are listed. 